\title{
BMI open International Atomic Energy Agency study with referring physicians on patient radiation exposure and its tracking: a prospective survey using a web-based questionnaire
}

\author{
Madan M Rehani, Theocharis Berris
}

\begin{abstract}
To cite: Rehani MM, Berris T. International Atomic Energy Agency study with referring physicians on patient radiation exposure and its tracking: a prospective survey using a web-based questionnaire. BMJ Open 2012;2:e001425. doi:10.1136/bmjopen-2012001425
\end{abstract}

- Prepublication history and additional material for this paper are available online. To view these files please visit the journal online (http://dx. doi.org/10.1136/bmjopen2012-001425).

Received 22 July 2012 Accepted 20 August 2012

This final article is available for use under the terms of the Creative Commons Attribution Non-Commercial 2.0 Licence; see http://bmjopen.bmj.com

International Atomic Energy Agency, Radiation Protection of Patients Unit, Vienna International Centre, Vienna, Austria

Correspondence to Dr Madan M Rehani; madan.rehani@gmail.com M.Rehani@iaea.org

\section{ABSTRACT}

Objectives: To assess the following themes among referring physicians: (A) importance of acquiring information about previous diagnostic exposures; (B) knowledge about radiation doses involved, familiarity with radiation units and, age-related radiosensitivity; (C) opinion on whether patients should be provided information about radiation dose and (D) self-assessment of appropriateness of referrals.

Design: A prospective survey using a web-based questionnaire.

Setting: International survey among referring physicians.

Participants: Referring physicians from 28 countries. Main outcome measures: Knowledge, opinion and practice of the four themes of the survey.

Results: All 728 responses from 28 countries (52.3\% from developed and $47.7 \%$ from developing countries) indicated that while the vast majority $(71.7 \%)$ of physicians feel that being aware of history of CT scans would always or mostly lead them to a better decision on referring patients for CT scans, only $43.4 \%$ often enquire about it. The majority of referring physicians $(60.5 \%)$ stated that having a system that provides quick information about patient exposure history would be useful. The knowledge about radiation doses involved is poor, as only one-third (34.7\%) of respondents chose the correct option of the number of chest $x$-rays with equivalence of a CT scan. In total, $70.9 \%$ of physicians stated that they do not feel uncomfortable when patients ask about radiation risk from CT scans they prescribe. Most physicians $(85.6 \%)$ assessed that they have rarely prescribed CT scans of no clinical use in patient management.

Conclusions: This first ever multinational survey among referring physicians from 28 countries indicates support for a system that provides radiation exposure history of the patient, demonstrates poor knowledge about radiation doses, supports radiation risk communication with patients and mandatory provisions for justification of a CT examination.

\section{ARTICLE SUMMARY}

Article focus

- How much value referring physicians attach to obtaining information about previous radiological examinations.

- Knowledge of referring physicians about the radiation doses, exposure units and age-related radiosensitivity.

- Opinion of referring physicians whether patients should be provided information about radiation dose.

Key messages

- Although the vast majority of physicians feel that knowing the previous history of CT scans would lead them to a better decision on referring patients for CT scan, only a few often ask about it.

- Knowledge about radiation doses involved in radiological examinations among referring physicians is poor.

- It indicates support for a system that provides radiation exposure history of the patient, supports radiation risk communication with patients and mandatory provisions for justification of a CT examination.

Strengths and limitations of this study

- This was the first ever prospective multinational survey among referring physicians from 28 countries, including five of the top six most populous countries, on a number of issues of vital interest while referring a patient for CT study. This study bears the bias typical with nonanonymised surveys. It was preferred to ask for contact email for seeking clarification which was done wherever necessary. Authors were aware about psychological aspects in respondents' choice for some questions.

\section{INTRODUCTION}

Good medical practice has historically been founded upon principles. The radiation 
protection principles, as laid down by the International Commission on Radiological Protection (ICRP), are justification and optimisation. ${ }^{1}$ Justification requires that the benefit for the patient must always outweigh the adjunct radiation risk. While clinical professionals are competent in estimating clinical benefit to an individual patient from a radiological procedure, consideration of radiation risk does not seem to have received the attention it deserves. In the past, particularly prior to the introduction of CT, radiological examinations were mostly dominated by plain X-rays (radiographs) where radiation doses and, hence, risks were trivial. The modern CT-based (including hybrid imaging such as positron emission tomography/CT, single photon emission $\mathrm{CT} / \mathrm{CT}$ ) and some of the nuclear imaging techniques employ radiation, that is equivalent to several hundreds of plain X-ray examinations and the frequency of recurrent use of these high-dose examinations is also high. ${ }^{23}$

Optimisation in radiological examinations falls within the domain of radiological professionals. Much work has been done globally and no week passes without some papers on patient dose optimisation being published in peer-reviewed journals, indicating significant momentum. Referring physicians play an important role in justification and appropriateness. Justification requires that the net benefit be positive. On the basis of papers that have been published so far, $20-40 \%$ of CT scans could be avoided if clinical decision guidelines were followed, although some studies provide still higher figures. ${ }^{3-5}$

About 3.6 billion diagnostic radiological examinations are being performed globally each year and the number is expected to increase in future. ${ }^{6}$ There is no evidence to indicate that inappropriate examinations are confined to only a few countries. Even if one takes an average figure for inappropriate examinations of $30 \%$, it amounts to 1.08 billion examinations per year. Such a large magnitude demands international attention and action. Appropriateness criteria and referral guidelines have been around for several decades. ${ }^{7-10}$ Most of these have been developed by radiology professionals with minimum, if any, involvement of referring physicians. Studies in the UK revealed very low awareness of the referral guidelines issued by the Royal College of Radiologists. ${ }^{11}$ Studies from other parts of the world also concur with the finding that physician awareness and utilisation of appropriateness guidelines are poor. ${ }^{12-15}$ The International Atomic Energy Agency (IAEA) launched a project several years ago called SmartCard/SmartRadTrack with the intention of tracking radiation exposure history of patients ${ }^{16}$ and felt that making available previous radiological examinations and associated radiation dose may provide additional tools to physicians in strengthening the process of justification. ${ }^{2}$ However, there are no data available on the importance referring physicians attach to radiation exposure history of patients.

The purpose of this first ever prospective multinational survey among referring physicians was to get their opinion on the value they attach to obtaining information about previous radiological examinations; their knowledge about the radiation doses, exposure units and age-related radiosensitivity involved; their opinion whether patients should be provided information about radiation dose; and self-assessment of appropriateness of their referrals.

\section{METHODS}

\section{Survey participants}

Since the survey was aimed at assessing the opinion of individual referring physicians rather than the official position of professional bodies, the questionnaire was sent to counterparts of about 40 countries participating in medical radiation protection projects of the IAEA. The counterpart is a person nominated by the Government for the medical radiation protection project. For each project with the IAEA, the counterpart is nominated by the Government. Counterparts were asked to forward the request to referring physicians in their country. There was no restriction regarding whom the questionnaire would be forwarded to. The only request was that it should be sent to physicians who refer patients for radiological examinations and not the radiologist or imaging physician. Wherever contact points for the IAEA projects were not available, such as in developed countries, the request was sent to personal contacts, for example medical physicists or radiology colleagues, asking them to pass on the questionnaire to referring physicians. Australia, Finland, India, Ireland, Spain, the UK and the USA were countries contacted through personal contacts and the rest through counterparts. The authors encouraged everyone to share the questionnaire with referring physician colleagues. This was desired in order to widen the participant base. Owing to differences in social and professional networks of counterparts and personal contacts, a variable number of responses originated from different countries.

\section{Survey contents}

A questionnaire containing 22 questions was prepared. These 22 questions were put together by the authors following wide interaction with referring physicians of various specialties from different countries. The Radiation Protection of Patients Unit (RPOP) of the IAEA has been in touch with referring physicians in an effort to increase appropriateness of referrals for radiological procedures. ${ }^{17}$ The survey was not piloted. However, in order to get an idea of the way it would be received by participants, after the questionnaire was populated with questions, the advice of a referring physician was sought. Twenty of these questions were multiple-choice questions and two were open questions for participants to provide free text answers. Table 1 lists all 22 questions grouped in four themes, namely: (A) Importance of acquiring information about previous diagnostic exposures of patients; (B) Knowledge of physician about radiation exposure from diagnostic examinations, familiarity with radiation units, and age-related 
Table 1 Breakdown of answers given by respondents to the questions of all subject areas

\begin{tabular}{|c|c|c|c|c|c|c|c|}
\hline Subject area tested & Question & Possible answers & $\begin{array}{l}\text { All } \\
\text { physicians }\end{array}$ & Consultants & Residents & $\begin{array}{l}\text { Developed } \\
\text { countries }\end{array}$ & $\begin{array}{l}\text { Developing } \\
\text { countries }\end{array}$ \\
\hline \multirow{37}{*}{$\begin{array}{l}\text { A. Importance of } \\
\text { acquiring information } \\
\text { about previous } \\
\text { diagnostic exposures } \\
\text { of patients }\end{array}$} & \multirow{5}{*}{$\begin{array}{l}\text { A.1. How often do you ask patients about } \\
\text { previous examinations involving radiation? }\end{array}$} & Never $(\mathrm{N})$ & $62(8.5)$ & $35(9.5)$ & $25(7.4)$ & $24(6.3)$ & $38(11.0)$ \\
\hline & & Occasionally (N) & $350(48.1)$ & $173(46.8)$ & $173(51.2)$ & $185(48.6)$ & $165(47.7)$ \\
\hline & & Very often $(P)$ & $204(28.1)$ & $110(29.7)$ & $85(25.1)$ & $115(30.2)$ & $89(25.7)$ \\
\hline & & Always $(P)$ & $111(15.3)$ & $52(14.1)$ & 55 (16.3) & 57 (15.0) & $54(15.6)$ \\
\hline & & No answer & 1 & 0 & 1 & 0 & 1 \\
\hline & \multirow{4}{*}{$\begin{array}{l}\text { A.2. What is the purpose of asking about } \\
\text { previous examinations using radiation? }\end{array}$} & Clinical Need (N) & 235 (32.4) & $123(33.2)$ & $100(29.7)$ & 109 (28.6) & $126(36.5)$ \\
\hline & & Radiation risk $(P)$ & $60(8.3)$ & $28(7.6)$ & $24(7.1)$ & $25(6.6)$ & 35 (10.1) \\
\hline & & Both (NEU) & $431(59.4)$ & 219 (59.2) & $213(63.2)$ & $247(64.8)$ & 184 (53.3) \\
\hline & & No answer & 2 & 0 & 2 & 0 & 2 \\
\hline & A.3. If a patient has undergone 10 or more & Yes $(P)$ & $611(84.3)$ & $310(84.0)$ & $290(85.8)$ & $349(91.6)$ & $262(76.2)$ \\
\hline & \multirow{8}{*}{$\begin{array}{l}\text { decision in prescribing next CT scan if the } \\
\text { clinical indications are not so demanding? } \\
\text { A.4. If you know that a patient has } \\
\text { undergone only one CT scan in the last } \\
2 \text { years, will it make it easier for you to } \\
\text { prescribe next CT scan? }\end{array}$} & No $(\mathrm{N})$ & $55(7.6)$ & $23(6.2)$ & $25(7.4)$ & $12(3.1)$ & $43(12.5)$ \\
\hline & & I do not know (NEU) & $59(8.1)$ & $36(9.8)$ & $23(6.8)$ & $20(5.2)$ & 39 (11.3) \\
\hline & & No answer & 3 & 1 & 1 & 0 & 3 \\
\hline & & Yes (N) & $432(59.3)$ & $218(58.9)$ & $197(58.1)$ & $211(55.4)$ & $221(63.7)$ \\
\hline & & No $(P)$ & $95(13.0)$ & $51(13.8)$ & $42(12.4)$ & $61(16.0)$ & $34(9.8)$ \\
\hline & & Not really $(P)$ & $164(22.5)$ & $76(20.5)$ & $88(26.0)$ & $101(26.5)$ & $63(18.2)$ \\
\hline & & I do not know (NEU) & $37(5.1)$ & $25(6.8)$ & $12(3.5)$ & $8(2.1)$ & $29(8.4)$ \\
\hline & & No answer & 0 & 0 & 0 & 0 & 0 \\
\hline & \multirow{4}{*}{$\begin{array}{l}\text { A.5. How frequently do you come across } \\
\text { situations where clinical indications are } \\
\text { enough to prescribe CT scan irrespective of } \\
\text { history of CT scans? }\end{array}$} & Very frequently $(\mathrm{N})$ & $292(40.1)$ & $153(41.4)$ & $136(40.1)$ & $149(39.1)$ & $143(41.2)$ \\
\hline & & Occasionally (NEU) & $298(40.9)$ & $139(37.6)$ & $154(45.4)$ & $158(41.5)$ & $140(40.3)$ \\
\hline & & Rarely $(\mathrm{P})$ & $138(19.0)$ & $78(21.1)$ & 49 (14.5) & $74(19.4)$ & $64(18.4)$ \\
\hline & & No answer & 0 & 0 & 0 & 0 & 0 \\
\hline & A.6. How often in your clinical practice do & Always $(P)$ & $160(22.0)$ & $87(23.5)$ & $67(19.8)$ & $63(16.5)$ & $97(28.0)$ \\
\hline & you think knowing history of previous CT & Mostly $(P)$ & $362(49.7)$ & $175(47.3)$ & 177 (52.2) & $198(52.0)$ & 164 (47.3) \\
\hline & \multirow[t]{3}{*}{ scans will help in making a better decision? } & Occasionally (N) & $159(21.8)$ & 83 (22.4) & $74(21.8)$ & $88(23.1)$ & $71(20.5)$ \\
\hline & & Rarely (N) & $47(6.5)$ & $25(6.8)$ & $21(6.2)$ & $32(8.4)$ & $15(4.3)$ \\
\hline & & No answer & & 0 & & & \\
\hline & \multirow{3}{*}{$\begin{array}{l}\text { A.7. If a patient has undergone radiological } \\
\text { examinations such that estimated dose is } \\
\text { about } 100 \mathrm{mSv} \text {, will this make it difficult for } \\
\text { you to prescribe another CT scan? }\end{array}$} & Yes $(P)$ & $484(67.2)$ & $263(71.5)$ & $215(64.0)$ & $238(62.5)$ & $246(72.6)$ \\
\hline & & No $(\mathrm{N})$ & 236 (32.8) & $105(28.5)$ & $121(36.0)$ & $143(37.5)$ & $93(27.4)$ \\
\hline & & No answer & 8 & 2 & 3 & 0 & 8 \\
\hline & \multirow{4}{*}{$\begin{array}{l}\text { A.8. Do you think having a system by which } \\
\text { you have quick information about patients' } \\
\text { exposure history will be helpful? }\end{array}$} & Yes $(P)$ & $440(60.5)$ & $237(64.1)$ & $188(55.6)$ & $196(51.4)$ & $244(70.5)$ \\
\hline & & Maybe (NEU) & 231 (31.8) & $106(28.6)$ & $122(36.1)$ & $148(38.8)$ & $83(24.0)$ \\
\hline & & Not really $(\mathrm{N})$ & $56(7.7)$ & 27 (7.3) & $28(8.3)$ & $37(9.7)$ & $19(5.5)$ \\
\hline & & No answer & 1 & 0 & 1 & 0 & 1 \\
\hline & \multirow{3}{*}{$\begin{array}{l}\text { A.9. Do you think that a CT scan should be } \\
\text { prescribed totally based on clinical indication, } \\
\text { irrespective of the age of the patient? }\end{array}$} & Yes (N) & 249 (34.3) & $124(33.6)$ & $116(34.3)$ & $106(27.8)$ & $143(41.4)$ \\
\hline & & $\begin{array}{l}\text { No, I consider age to be an } \\
\text { important factor when making } \\
\text { a decision }(P)\end{array}$ & $477(65.7)$ & $245(66.4)$ & $222(65.7)$ & 275 (72.2) & $202(58.6)$ \\
\hline & & No answer & 2 & 1 & 1 & 0 & 2 \\
\hline
\end{tabular}


Table 1 Continued

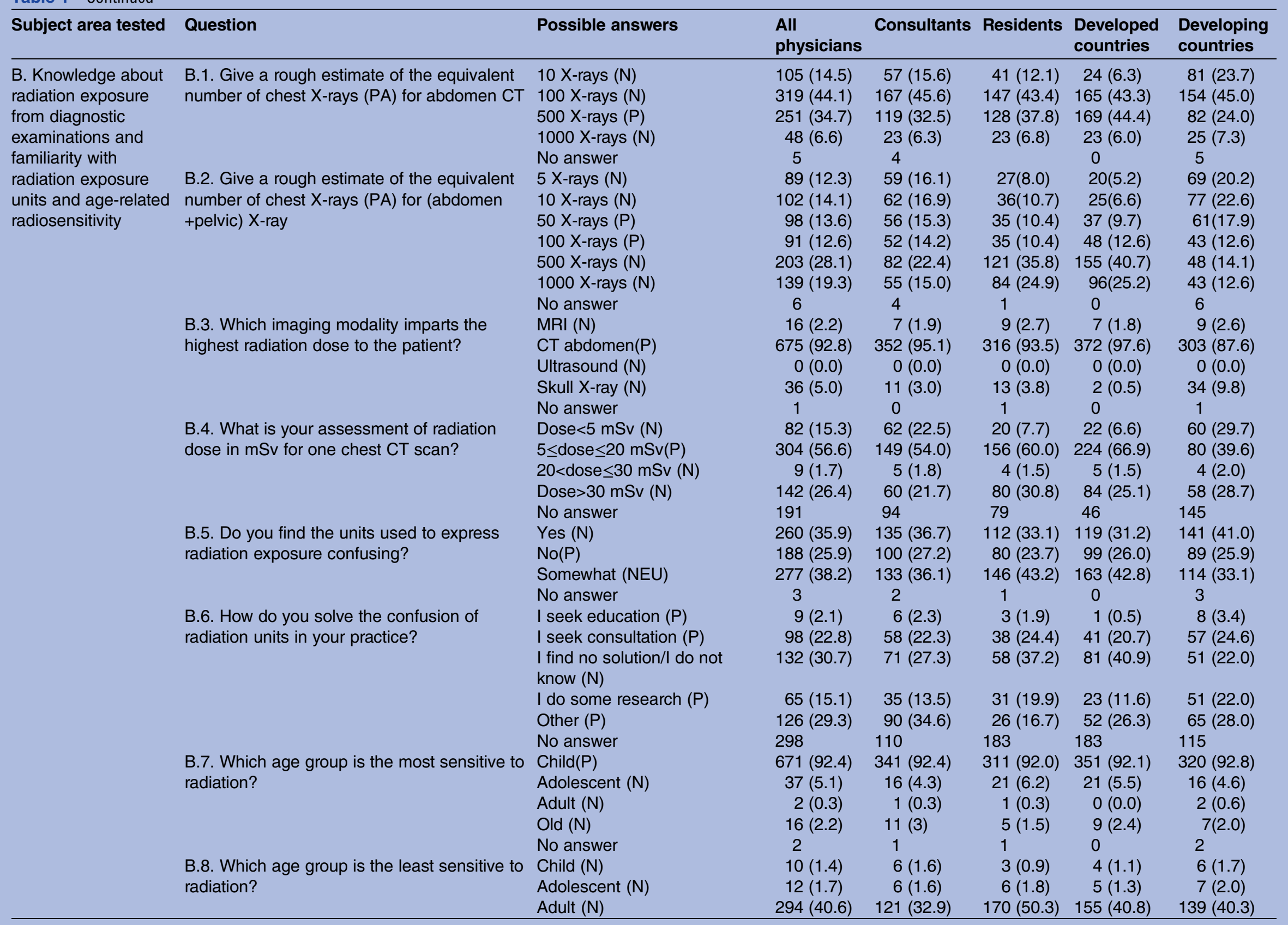


Table 1 Continued

\section{Subject area tested}

\section{Question}

Possible answers

All

\section{Old (P)}

No answer

C. Opinions on whether patients

should be provided

with information

about dose from their

medical exposure to

radiation

C.1. How often do you come across patients

Very often (NEU)

who discuss the radiation dose issue with Occasionally (NEU)

you before getting the investigation done?

Very rarely (NEU)

Never (NEU)

No answer

C.2. Do you feel uncomfortable when a $\quad$ Yes (N)

patient asks you about radiation risk from the $\mathrm{No}(\mathrm{P})$

CT scan that you are prescribing?

Mildly (NEU)

No answer

C.3. Should patients be provided information Yes $(P)$

about radiation dose in the report of a CT

No $(\mathrm{N})$ examination?

C.4. If it was made mandatory that physicians should give written justification whenever a CT examination is prescribed, will you be comfortable with that?

\section{I do not bother (NEU)}

No answer

No problem with me $(P)$

I do not think it should be required $(\mathrm{N})$

It will be very helpful in achieving better radiation protection $(\mathrm{P})$

No answer

D. Self-assessment D.1. How often have you ordered a CT scan of appropriateness of that you subsequently realised was of no Very often $(P)$ referral clinical use in patient management?

Often $(P)$

Rarely (N) No answer

Answers given by all physicians are shown. Percentages as fractions of total responses to each answer are provided in parentheses. answer to each question is also shown. The notations (P), (N), (NEU) beside the possible answers represent the coding of responses for the evaluation of the themes represented by each group of questions. 
radiosensitivity; (C) Opinion on whether patients should be provided information about radiation dose and (D) Self-assessment of appropriateness of referrals. The questions in the questionnaire were randomised and the themes were not provided to participants to avoid bias. Demographic information pertaining to specialty, subspecialty and level of experience (resident and consultant) besides country and contact particulars was also collected.

\section{Survey administration}

The survey was coordinated by the IAEA. It was primarily planned for online data entry through Google spreadsheets. Microsoft Word (Microsoft, Corporation, Redmond, Washington, USA)-based copies were also made available to those who found it more convenient. The distribution of questionnaire files and links to the online Google form started at the end of August 2011 and pooling of answers was started in mid-November 2011. The participants completed this questionnaire online and no restriction was imposed in terms of consultation with other colleagues or looking up literature.

\section{Survey analysis}

Responses from radiologists, radiation oncologists and nuclear medicine physicians were excluded from the analysis. Numbers of respondents who selected a specific answer in a question and the corresponding percentages of each answer were estimated as a fraction of the total number of physicians who answered the specific question. For the open question B.4, 'What is your assessment of radiation dose in $\mathrm{mSv}$ for one chest CT scan?', the answers received were classified in the following range: $<5,5$ to $\leq 20,21$ to $\leq 30$ and $>30$.

A meeting was held at the IAEA headquarters in Vienna on 26-28 September 2011 in which 19 participants from 16 countries and among them a representative of the WHO were present. In total, 58\% were referring physicians. This meeting provided an opportunity to obtain valuable feedback on the interpretation and presentation of the study results. ${ }^{17}$

Two-tailed Fisher's exact test was used in order to assess whether there were statistically significant differences in answers between physicians working in developed versus developing countries and residents versus consultants. Classification of countries in developed and developing follows the International Monetary Fund (IMF) classification as presented in the IMF report: 'World Economic Outlook: Slowing growth, rising risks' of September 2011. ${ }^{18}$ During the analysis, possible answers for each question were characterised as positive $(\mathrm{P})$, negative $(\mathrm{N})$, or neutral (NEU) and pooled for each one of the themes (A, B and $\mathrm{C}$; table 1$)$. If the positive answers per theme per participant were more than the negative ones, the participant's position was counted as positive for the respective theme. The opposite occurred where most of the responses were negative. A participant providing equal numbers of positive and negative answers in a theme was counted as neutral for the respective theme. If a participant had provided no answer in some question(s) those were not coded and thus not counted. Statistical calculations were carried out using QuickCalcs, GraphPad Software online calculator (GraphPad Software, Inc, La Jolla, California, USA) ${ }^{19}$ Probability values lower than 0.05 were considered to represent statistically significant differences.

\section{Role of the funding source}

There was no funding source for this work. The corresponding author had full access to all the data in the study, and had final responsibility for the decision to submit for publication.

\section{RESULTS}

\section{Demographic data}

A total of 767 responses were received. Thirty-nine were excluded as they were from radiologists, nuclear medicine physicians, or radiation oncologists. Thus, 728 pertaining to only referring physicians were used for further analysis. Responses originated from 28 countries. In total, $381(52.3 \%)$ responses were from developed countries and the remaining $347(47.7 \%)$ from developing countries. Figure 1 exemplifies the relative magnitude of the two groups of physicians. The distribution of responses under the developed countries category and the number of responses (in parentheses) is: Australia (1), Cyprus (3), Czech Republic (268), Finland (90), Ireland (1), Slovenia (4), Spain (1), the UK (1), the USA (12). Accordingly, for 347responses from developing countries, Armenia (2), Bulgaria (1), Brazil (26), China, Peoples Republic of (5), Croatia (37), Macedonia, Former Yugoslav Republic of (41), Georgia (2), Hungary (14), India (50), Indonesia (24), Iran (16), Kazakhstan (15), Lebanon (12), Lithuania (2), Malaysia (14), Moldova, Republic of (4), Pakistan (43), Philippines (21) and Sri Lanka (18). Of 728 respondents, 339 (46.6\%) were residents, $370(50.8 \%)$ were consultants and $19(2.6 \%)$ did not provide data about level of expertise. An overview of all the answers for each question is given in table 1 .

\section{Importance of acquiring information about previous diagnostic exposures of patients}

Table 2 presents results against each theme of the questionnaire. Responses to question A.1 showed that

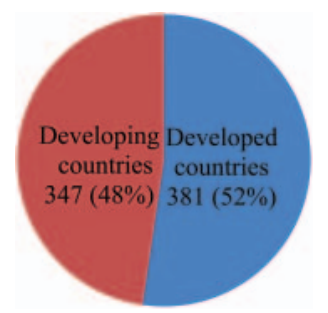

Figure 1 Graphic representation of the relative size of the groups of survey participants originating from developing and developing countries. 
Table 2 Position of respondents regarding the themes tested in this study

\begin{tabular}{|c|c|c|c|c|c|c|c|c|c|c|}
\hline & \multicolumn{2}{|c|}{ All physicians } & \multicolumn{2}{|c|}{ Consultants } & \multicolumn{2}{|c|}{ Residents } & \multicolumn{2}{|c|}{$\begin{array}{l}\text { Developed } \\
\text { countries }\end{array}$} & \multicolumn{2}{|c|}{$\begin{array}{l}\text { Developing } \\
\text { countries }\end{array}$} \\
\hline & (P) & $\begin{array}{l}\text { (N) or } \\
\text { (NEU) }\end{array}$ & (P) & $\begin{array}{l}\text { (N) or } \\
\text { (NEU) }\end{array}$ & (P) & $\begin{array}{l}\text { (N) or } \\
\text { (NEU) }\end{array}$ & (P) & $\begin{array}{l}\text { (N) or } \\
\text { NEU }\end{array}$ & (P) & $\begin{array}{l}\text { (N) or } \\
\text { (NEU) }\end{array}$ \\
\hline $\begin{array}{l}\text { A. Importance of acquiring } \\
\text { information about previous } \\
\text { diagnostic exposures of patients }\end{array}$ & $\begin{array}{l}474 \\
(65.1)\end{array}$ & $\begin{array}{l}254 \\
(34.9)\end{array}$ & $\begin{array}{l}246 \\
(66.5)\end{array}$ & $\begin{array}{l}124 \\
(33.5)\end{array}$ & $\begin{array}{l}220 \\
(64.9)\end{array}$ & $\begin{array}{l}119 \\
(35.1)\end{array}$ & $\begin{array}{l}253 \\
(66.4)\end{array}$ & $\begin{array}{l}128 \\
(33.6)\end{array}$ & $\begin{array}{l}221 \\
(63.7)\end{array}$ & $\begin{array}{l}126 \\
(36.3)\end{array}$ \\
\hline $\begin{array}{l}\text { B. Knowledge about radiation } \\
\text { exposure from diagnostic } \\
\text { examinations and familiarity with } \\
\text { radiation exposure units and } \\
\text { age-related radiosensitivity }\end{array}$ & $\begin{array}{l}468 \\
(64.3)\end{array}$ & $\begin{array}{l}260 \\
(35.7)\end{array}$ & $\begin{array}{l}256 \\
(69.2)\end{array}$ & $\begin{array}{l}114 \\
(30.8)\end{array}$ & $\begin{array}{l}200 \\
(59.0)\end{array}$ & $\begin{array}{l}139 \\
(41.0)\end{array}$ & $\begin{array}{l}259 \\
(68.0)\end{array}$ & $\begin{array}{l}122 \\
(32.0)\end{array}$ & $\begin{array}{l}209 \\
(60.2)\end{array}$ & $\begin{array}{l}138 \\
(39.8)\end{array}$ \\
\hline $\begin{array}{l}\text { C. Opinions on whether patients } \\
\text { should be provided with } \\
\text { information about dose from their } \\
\text { medical exposure to radiation }\end{array}$ & $\begin{array}{l}588 \\
(80.8)\end{array}$ & $\begin{array}{l}140 \\
(19.2)\end{array}$ & $\begin{array}{l}299 \\
(80.8)\end{array}$ & $\begin{array}{l}71 \\
(19.2)\end{array}$ & $\begin{array}{l}280 \\
(82.6)\end{array}$ & $\begin{array}{l}59 \\
(17.4)\end{array}$ & $\begin{array}{l}320 \\
(84.0)\end{array}$ & $\begin{array}{l}61 \\
(16.0)\end{array}$ & $\begin{array}{l}268 \\
(77.2)\end{array}$ & $\begin{array}{l}79 \\
(22.8)\end{array}$ \\
\hline
\end{tabular}

physicians rarely ask patients about previous radiological examinations (never $8.5 \%$ and occasionally $48.1 \%$ against very often $28.1 \%$ and always $15.3 \%$ ). In question A.2, nearly two-thirds $(67.7 \%)$ preferred to choose the purpose of asking about previous radiological examinations as 'both' radiation risk, and clinical need or radiation risk only. In question A.3, the vast majority of physicians $(84.3 \%)$ state that their decision would be affected if they knew that a patient has undergone 10 or more CT scans in the last 2 years. The situation is similar for question A.7 where $67.2 \%$ stated that they would find it difficult to prescribe a next CT scan to a patient who has already received a dose of about $100 \mathrm{mSv}$. The answers to question A.4 also concurred with the idea that patients who have received higher doses are harder to be referred for a next examination. In question A.5, 'How frequently do you come across situations where the clinical indications are enough to prescribe a CT scan irrespective of the previous history of CT scans?', the choice 'rarely' was opted by a very small number of respondents (19.0\%), and an almost equal number of responses were for 'very frequently' $(40.1 \%)$ and 'occasionally' (40.9\%). Two-thirds $(65.7 \%)$ considered patient age to be an important factor in their decision-making for referring patients for CT investigations (A.9).

The vast majority of physicians (71.7\%) stated that knowing the history of previous CT scans would always, or mostly, help them in making a better decision (A.6). This concurs with their opinion expressed against question A.8, that a system providing them with quick information about patient exposure history will be helpful $(60.5 \%)$. Only $7.7 \%$ responded 'not really' in question A.8, thus indicating strong support for utility of tracking. Figure 2 depicts the percentages for all answers in question A.8.
For theme A, overall $65.1 \%$ of physicians had a positive position regarding the importance of acquiring information about previous patient exposures (table 3). This study did not find any statistically significant differences among physicians in different categories.

\section{Knowledge about radiation units and age-related radiosensitivity}

Only one-third $(34.7 \%)$ of respondents chose the correct option of the number of chest X-rays with equivalence of an abdominal CT scan. Over half (58.6\%) of the physicians underestimated the abdominal CT scan dose (in terms of chest X-ray equivalent). Only a small percentage (13.6\% and $12.6 \%)$ provided the correct answer of 50 and 100 X-ray equivalence, respectively (B.2). Figure 3 shows how random the received answers were. Overall, $47.4 \%$ of participants overestimated the dose from abdominal and pelvic X-rays. In question B.3, the vast majority $(>90 \%)$ of respondents answered correctly on which imaging modality imparts the highest radiation dose. Surprisingly, $2.2 \%$ of respondents chose a totally incorrect answer (MRI), with another 5\% choosing

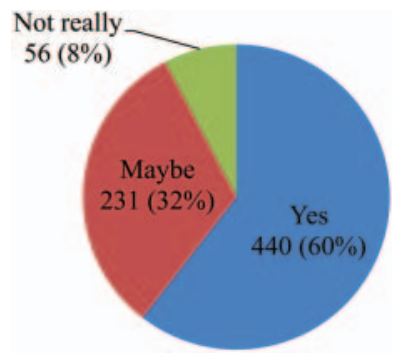

Figure 2 Overall answers of participants regarding their opinion on whether having a system by which they would have quick information about patient-exposure history would be helpful (question A.8.). 
Table 3 Statistical analysis results for the different themes and groups of physicians studied in this work

\begin{tabular}{|c|c|c|c|c|}
\hline Theme & $\begin{array}{l}\text { Groups under } \\
\text { comparison }\end{array}$ & & p Value & $\begin{array}{l}\text { Statistically } \\
\text { significant }\end{array}$ \\
\hline \multirow{2}{*}{$\begin{array}{l}\text { A. Importance of acquiring information about previous } \\
\text { diagnostic exposures of patients }\end{array}$} & Consultants & Residents & 0.6923 & No \\
\hline & $\begin{array}{l}\text { Developed } \\
\text { countries }\end{array}$ & $\begin{array}{l}\text { Developing } \\
\text { countries }\end{array}$ & 0.4836 & No \\
\hline B. Knowledge about radiation exposure from diagnostic & Consultants & Residents & 0.0048 & Yes \\
\hline $\begin{array}{l}\text { examinations and familiarity with radiation exposure } \\
\text { units and age-related radiosensitivity }\end{array}$ & $\begin{array}{l}\text { Developed } \\
\text { countries }\end{array}$ & $\begin{array}{l}\text { Developing } \\
\text { countries }\end{array}$ & 0.0304 & Yes \\
\hline C. Opinions on whether patients should be provided & Consultants & Residents & 0.5610 & No \\
\hline $\begin{array}{l}\text { with information about dose from their medical } \\
\text { exposure to radiation }\end{array}$ & $\begin{array}{l}\text { Developed } \\
\text { countries }\end{array}$ & $\begin{array}{l}\text { Developing } \\
\text { countries }\end{array}$ & 0.0238 & Yes \\
\hline
\end{tabular}

another incorrect answer of skull X-ray. In open question B. 4 on 'What is your assessment of radiation dose in $\mathrm{mSv}$ for one chest CT scan?', overall, $56.6 \%$ answered 'dose is between 5 and $20 \mathrm{mSv}$ ' which was considered to be the correct range. Almost $75 \%$ of physicians stated that they find radiation units confusing $(35.9 \%$ confusing and $38.2 \%$ somewhat confusing). For the open question B.6, 'How do you solve the confusion of radiation units in your practice?' the answers received were found to belong in one of the following categories: I seek consultation, I seek education, I do some research, I find no solution/I do not know. A large number of physicians (298) did not answer and $30.7 \%$ of those who answered responded that they do not solve the problem at all.

A satisfying $92.4 \%$ of participants answered correctly to question B.7, concerning the most radiosensitive patient group. In question B.8, regarding the least radiosensitive group of patients, $56.4 \%$ of participants answered correctly. A considerable percentage of $40.6 \%$ erroneously answered that the least radiosensitive group is adult patients.

Tables 2 and 3 show that significantly more consultants $(69.2 \%)$ than residents $(59.0 \%)$ provided more correct than wrong answers in the questions of theme B and, thus, they appeared to be more knowledgeable about radiation doses and age-related radiosensitivity $(\mathrm{p}=0.0048)$. Similarly, physicians coming from developed countries were significantly more knowledgeable than those from developing countries $(\mathrm{p}=0.0304)$.

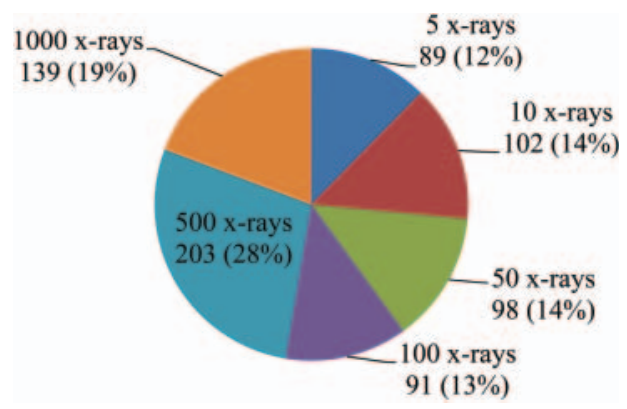

Figure 3 Overall answers of participants regarding their estimation of equivalent number of chest $X$-rays for (abdomen+pelvic) X-ray (question B.2.).
Opinions on whether patients should be provided information about their radiation dose and risks

The majority of physicians $(71.7 \%)$ stated that they very rarely or never come across patients who discuss the radiation dose issue with them. In total, $70.9 \%$ stated that they do not feel uncomfortable when patients ask about radiation risk from CT scans they prescribe. In question C.3, $80.1 \%$ of participants stated that information about radiation dose in CT should be provided to patients in the report of the examination or that they would not bother if patients were provided with that information. In question C.4, 27.4\% of physicians stated that mandatory written justification of CT scans would be very helpful in achieving better radiation protection, while another $47.9 \%$ appeared to have no problem with that, thus totalling to $75.3 \%$.

Significantly more physicians from developed countries were found to be positive regarding the notion of theme $\mathrm{C}$ in favour of providing patients with information about dose prior to their radiation exposure $(p=0.0238)$. Overall, $80.8 \%$ were positive regarding theme $\mathrm{C}$, in favour of providing information to patients.

\section{Physicians' self-assessment of appropriateness of referral}

The majority of physicians answered that they have rarely prescribed a CT scan which they subsequently realised was of no clinical use. Only $8.7 \%$ of consultants think that on retrospective hindsight they often or very often ordered a CT scan of no clinical usefulness. Significantly more residents provided similar answers in comparison with senior consultants $(16.3 \%, \mathrm{p}=0.0027)$.

\section{DISCUSSION}

This was the first ever prospective multinational survey among referring physicians from 28 countries, including five of the top six most populous countries, on the value they attach to obtaining information about previous radiological examinations; their knowledge about the radiation doses, exposure units, and age-related radiosensitivity involved; opinion whether patients should be provided information about radiation dose; and self-assessment of appropriateness of their referrals. It is clear that while the vast majority $(71.7 \%)$ of physicians 
feel that knowing the history of CT scans would always or mostly lead them to a better decision on referring patients for a CT scan (A.6), only $43.4 \%$ often ask about it (A.1). Significantly more physicians in developing countries $(36.5 \%)$ than in developed countries $(28.6 \%)$ claimed to ask about previous examinations for clinical purposes only $(\mathrm{p}=0.0261)$. Under the IAEA SmartCard/ SmartRadTrack project, manufacturers of imaging equipment have been motivated to provide the possibility of display on the computer screen of all previous radiological examinations a patient has undergone by clicking on a patient identifier. Accordingly, a separate question on the utility of such a system was included. The majority of referring physicians $(60.5 \%)$ stated that having a system which provides quick information about patient exposure history would be useful. It was also deemed necessary to have the referring physician's views on whether the considerations for CT examination referral are based solely on clinical considerations, or whether the radiation risk forms part of the process of justification. About two-thirds $(65.7 \%)$ of respondents felt that a patient's age (from radiation risk perspective) should form part of the justification process in addition to clinical history. Unfortunately, 16 physicians in the study counted MRI as the imaging modality that delivers the highest radiation dose to patients. Although the number is small ( 16 of $728=2.2 \%$ ), it is nevertheless rather disappointing that the level of awareness is so poor as not to know that radiation from MRI machines is not the same as X-rays. This question was deliberately designed to be unambiguous and strong so as to remove fence sitters and, thus, the authors did not anticipate anyone to choose MRI. Strangely, such a response was not restricted to residents, but there were also consultants from five different countries. Luckily, there were zero responses in favour of ultrasound against the same question. A considerable $26.4 \%$ of physicians in this survey gave high estimates of radiation dose to patients of more than $30 \mathrm{mSv}$ for a chest CT. This is not so surprising, as most physicians have little or no idea about dose in $\mathrm{mSv}$ and their answers would have been based on purely guess work. Only about one-third $(34.7 \%)$ could provide the correct answer against equivalence of chest X-ray for an abdomen CT scan and 26.2\% for another question indicating equivalence of chest X-ray to abdomen and pelvic X-ray in terms of radiation dose. Surprisingly, $2.2 \%$ stated the right age group for highest sensitivity to radiation as old age rather than childhood. Physicians in developing countries were found to be less knowledgeable about theme B of the questionnaire. This indicates the need for increasing awareness in the developing countries of the world. It is very encouraging that physicians overall appeared to be comfortable with provision of information about radiation dose to patients. A considerable fraction $(75.3 \%)$ supports the view to make it mandatory for physicians to give written justification whenever a CT examination is prescribed.
Although referring physicians from many parts of the world participated in this study, it is anticipated that the results produced are indicative of the global situation, but certainly further research is needed to evaluate the situation within each country. Regarding the global situation, the high number of respondents could be considered to be giving a representative overview of the situation. It is expected that for countries with diverse socioeconomic environments, physicians' experience, training and knowledge, there would be variations. This study also bears the bias with non-anonymised surveys. It was preferred to ask for contact emails for seeking clarification which was done wherever necessary. The authors were conscious about psychological aspects or self-interest in respondents' choices for some questions in groups A and C. For example, question A.7. could induce thoughts of liability to a physician's mind. Question D.1. is another example as it asks physicians to assess the quality of their own practice. It should be stressed here that the voluntary basis on which this study was conducted softens the effect on results. The study was based on voluntary response from the participants and thus it was impossible to estimate possible nonresponse bias. Possible selection bias and corresponding unknown uncertainties could be existing in this work. However, the authors believe that this effect was minimised by the free dissemination of the online survey link and electronic document file among physicians without any intervention from the authors and the fact that the respondent did not know the purpose of the survey as the title of the survey was: IAEA Questionnaire for Referring Physicians on Diagnostic use of Radiation. It did not mention 'patient exposure tracking'.

The topic of accounting for previous radiological exposures being relatively new, even with the radiological community where technology has only recently started providing solutions for tracking, not much published literature was anticipated. However, studies on information about physicians' utilisation of imaging appropriateness guidelines were identified, most of them stating that the clinicians' use of guidelines is poor and their awareness about such tools is limited. ${ }^{12-15}$ Studies including information on lack of clinicians' knowledge about radiation dose were also found. ${ }^{20}{ }^{21}$ All these studies were performed within a single country. We identified only one study addressing justification practice of clinicians in Norway. ${ }^{22}$ This is the first ever prospective multinational survey among referring physicians from 28 countries, including five of the top six most populous countries. Participants in this survey comprised a representative sample of physicians coming from developed as well as developing countries. The numbers of participants from developed and developing countries were comparable (381 against 347). The same holds true for the number of participants at different levels of experience (370 consultants against 339 residents). The participants from Czech Republic were many as the counterpart had utilised the attendance of referring physicians in a mandatory 
training course and distributed the questionnaire at the beginning of the course to participants.

To the best of our knowledge, there is no multinational study evaluating so many aspects of physicians' practice regarding radiation utilisation and its appropriateness. This study elucidated that while referring physicians consider it important to know about previous radiological examinations, they barely do it in practice. Our results demonstrate poor knowledge of physicians on radiation doses involved in CT examinations, some among them thinking that MRI involves the highest radiation dose to patients, and lack of awareness on the least radiosensitive age. Some aspects of these results agree with the results presented by Borgen $e t a l^{22}$ that physicians tend to underestimate the doses of high-dose modalities such as CT dose. With growing awareness among patients and their need to know about radiation risks, it was pleasant to learn that $70.9 \%$ of physicians do not feel uncomfortable when patients ask about radiation risk. Further, much as though regulatory provisions are not particularly liked and voluntary methods should be given priority, the counter move to defensive medicine which makes physicians comfortable in asking for CT examinations rather than not asking may possibly be to regulate and request special justification while referring a patient for a CT scan. This is in line with the view expressed by Brenner and Hricak ${ }^{4}$ asking for legislative provisions in the light of compelling and continuing overprescription of CT scans. Interestingly, $75.3 \%$ of respondents in this survey support the view to make it mandatory for physicians to give written justification whenever a CT examination is prescribed. Further research could include more detailed studies to assess the situations and possible differences within single countries or among countries. These studies could help in elucidating the details regarding the template for implementation of dose tracking in clinical settings locally and at higher levels.

A small component of this work was presented at the Beebe Symposium entitled 'Tracking Radiation Exposure from Medical Diagnostic Procedures' organised by the National Academies, USA on 8-9 December 2011, Washington DC.

Acknowledgements The authors wish to sincerely thank counterparts and contacts who helped in passing on the survey questionnaire to referring physicians. In particular help by Mr Leos Novak (Czech Republic), Dr Randeep Guleria (India), Ms Areesha Zaman and Dr Maham Zaman (Pakistan), and Dr Raija Seuri (Finland) are gratefully acknowledged. A special thanks is due to the Unit secretary Jacqueline Dorcas Neufing for carrying out English language check.

Contributors MMR had the original idea and concept for this work. Both MMR and TB were responsible for study design, literature search, data collection and interpretation, drafting, reviewing and writing of the paper. Statistical calculations were carried out by TB. All authors had full access to all the data (including statistical reports and tables) in the study and can take responsibility for the integrity of the data and the accuracy of the data analysis.
Competing interests None.

Provenance and peer review Not commissioned; externally peer reviewed.

Data sharing statement Extra data can be accessed via the Dryad data repository at http://datadryad.org/ with the doi:10.5061/dryad.3hq09.

\section{REFERENCES}

1. International Commission on Radiological Protection (ICRP). The 2007 Recommendations of the International Commission on Radiological Protection. ICRP Publication 103. Ann ICRP 2007;37.2010;(2-4):1-332.

2. Rehani M, Frush D. Tracking radiation exposure of patients. Lancet 2010;376:754-5.

3. Sodickson A, Baeyens PF, Andriole KP, et al. Cumulative radiation exposure, and associated radiation-induced cancer risks from CT of adults. Radiology 2009;251:175-84.

4. Brenner DJ, Hricak $\mathrm{H}$. Radiation exposure from medical imaging: time to regulate? JAMA 2010;304:208-9.

5. Brenner DJ. Medical imaging in the 21 st century-getting the best bang for the rad. N Engl J Med 2010;362:943-5.

6. United Nations Scientific Committee on the Effects of Atomic Radiation, Sources and Effects of Ionizing Radiation, Volume I: Report to the General Assembly, Scientific Annexes A and B. UNSCEAR Report 2008, United Nations, New York, 2008.

7. Royal College of Radiologists. Making the best use of a department of clinical radiology, 5th edn, London, UK: Royal College of Radiologists, 2003.

8. European Commission. Radiation protection 118. Referral guidelines for imaging. European Commission, Directorate-General for Energy and Transport, 2007. http://ec.europa.eu/energy/nuclear/radioprotection/ publication/doc/118_update_en.pdf (accessed 26 Jan 2012).

9. American College of Radiology. ACR Appropriateness Criteria®. http://www.acr.org/secondarymainmenucategories/quality safety/ app_criteria.aspx (accessed 26 Jan 2012).

10. Diagnostic imaging pathways. A clinical decision support tool and educational resource for diagnostic imaging. Government of Western Australia, Department of Health. http://www. imagingpathways.health.wa.gov.au/includes/index.html (accessed 26 Jan 2012).

11. Kumar S, Mankad K, Bhartia B. Awareness of making the best use of a Department of Clinical Radiology amongst physicians in Leeds Teaching Hospitals, UK. BJR 2007;80:140.

12. Dillon JE, Slanetz PJ. Teaching evidence-based imaging in the radiology clerkship using the ACR appropriateness criteria. Acad Radiol 2010;17:912-16.

13. Hirschl DA, Ruzal-Shapiro C, Taragin BH. Online survey of radiologic ordering practices by pediatric trainees. J Am Coll Radiol 2010;7:360-3

14. Bautista AB, Burgos A, Nickel BJ, et al. Do clinicians use the American College of Radiology appropriateness criteria in the management of their patients? AJR 2009;192:1581-5.

15. Chiunda AB, Mohammed TL. Knowledge of ACR thoracic imaging appropriateness criteria among trainees: one institution's experience. Acad Radiol 2012;19:635-9.

16. Rehani MM, Frush DP. Patient exposure tracking: The IAEA Smart Card Project. Radiat Prot Dosimetry 2011;147:314-16.

17. Radiation Protection of Patients Website, International Atomic Energy Agency. Summary of the first meeting on radiation protection for referring physicians. https://rpop.iaea.org/RPOP/RPoP/ Content/News/summary-first-meeting-referring-physicians.htm.

18. International Monetary Fund (IMF). World Economic Outlook: slowing growth, rising risks. International Monetary Fund, Washington, D. C., 2011.

19. GraphPad Software, Inc. Quickcalcs. Online calculator for scientists. http://www.graphpad.com/quickcalcs/index.cfm (accessed 26 Jan 2012).

20. Shiralkar S, Rennie A, Snow M, et al. Doctors' knowledge of radiation exposure: questionnaire study. BMJ 2003;327:371-2.

21. Krille L, Hammer GP, Merzenich $\mathrm{H}$, et al. Systematic review on physician's knowledge about radiation doses and radiation risks of computed tomography. Eur J Radiol 2010;76:36-41.

22. Borgen L, Stranden E, Espeland A. Clinicians' justification of imaging: do radiation issues play a role? Insights Imaging 2010;1:193-200. 